\title{
Personality Types as Moderators of the Acceptance of Information Technologies in Organizations: A Multi-Group Analysis in PLS-SEM
}

\author{
Patricio Ramírez-Correa ${ }^{1, *(0)}$, Elizabeth E. Grandón ${ }^{2}{ }^{\mathbb{C}}$, Jorge Alfaro-Pérez ${ }^{1}$ and \\ Giselle Painén-Aravena ${ }^{1}$ \\ 1 School of Engineering, Universidad Católica del Norte, Larrondo, Coquimbo 1780000, Chile \\ 2 Department of Information Systems, Universidad del Bío-Bío, Avda, Collao, Concepción 4030000, Chile \\ * Correspondence: patricio.ramirez@ucn.cl; Tel.: +56-51-220-9899
}

Received: 6 June 2019; Accepted: 10 July 2019; Published: 23 July 2019

\begin{abstract}
This study aims to examine the influence of personality types on the acceptance of information technologies at work. Based on the model of the five dominant personality traits and the unified theory of acceptance and use of technology, 155 users of Enterprise Resource Planning systems were examined in two Chilean organizations. A cluster analysis applied to personality traits identified three different types of personalities. Subsequently, a multi-group analysis in Partial Least Squares of the technology acceptance model detected statistically significant differences among these types of personalities. Specifically, although for all personality types, the intention to use technology is explained in more than 60 percent, the strength of the antecedent variables changes radically depending on the type of personality. These findings indicate that personality type plays an essential role as a moderator of technology acceptance at work. This study is one of the first attempts where personality types, instead of specific personality traits, have been associated with technology acceptance models. In it, we performed an analysis of statistically significant differences among the types. Its practical implications are to identify the personality type of employees and adapt the implementation of innovations accordingly. This can help organizations to implement technology successfully, which, in turn, contributes to their sustainability.
\end{abstract}

Keywords: five factor model; unified theory of acceptance and use of technology; PLS-MGA; ERP systems

\section{Introduction}

An Enterprise Resource Planning (ERP) system helps organizations to support and integrate business functions and ensure their operations are appropriately set, which, in turn, help them to achieve long-term growth and sustainability [1]. Successful implementation is an essential factor when studying the intellectual structure of ERP systems [2]. Shiau (2016) [2] performed a co-citation analysis of thousands of articles to examine the knowledge structures involved in ERP studies, and concluded that the implementation of an ERP is challenging, and each organization exhibits specific considerations. Thus, the study of acceptance and success of information technology in organizations is an important subject to be studied in order to obtain sustainability and competitive advantage.

The seminal work of Fishbein and Ajzen (1975) [3], from the social psychology area, set the basis for understanding technology adoption through the prism of information systems research. The authors proposed the Theory of Reasoned Action, which states that a person's intention to perform a certain type of behavior, in this case adopting technology, is the main predictor of whether or not he or she will perform that behavior. They stated that the person's attitude toward the behavior and the 
subjective norm determine intention. Attitude toward the behavior refers to the degree to which a person has a favorable or unfavorable evaluation of the behavior in question. Subjective norm, on the other hand, refers to the perceived social pressure to perform, or not to perform, the behavior. Other theories, such as the Technology Acceptance Model (TAM) [4], the Theory of Planned Behavior [5], and the Unified Theory of Acceptance and Use of Technology (UTAUT) [6] have focused their attention on explaining behavior based on personal beliefs without taking into account the personality traits of the individuals.

The study of Zmud (1979) [7] was one of the first to assess the importance of individual differences in information technology success. After analyzing empirical literature, Zmud concluded that individual differences are a significant force in determining the success of information systems and technology. Based upon these findings, extensive research has been conducted considering the impact of human factors, including the unique characteristics of the users, on the adoption and effectiveness of information technology [8-11]. Most of these studies have used the five-factor model (FFM) [12] to assess personal characteristics. The FFM proposes the existence of five traits: neuroticism, extraversion, openness, agreeableness, and conscientiousness, that capture the core domains of personality [13]. These traits have been hypothesized as external, moderators, and observed categorical moderator variables within different theoretical frameworks [14-16].

It is worth noting the work of Devolder et al. (2012) [16] as an example of the use of personality traits as categorical moderators [17]. They explored the acceptance of an electronic patient record using the taxonomy of three types of personalities associated with the FFM and the categories related to different profiles of technology consumers according to the Technology Readiness Index (TRI). From these classifications, the users of a hospital information system were grouped, and then the authors determined the variables that predict the attitude toward the system, considering the independent variables of the UTAUT theory. As a result of this procedure, Devolder et al. (2012) [16] report that according to the group analyzed, the variables that significantly determine attitude change. However, the choice of attitude as a dependent variable in Devolver et al.'s work is atypical, since the attitude toward the system does not integrate UTAUT. Indeed, several authors have rejected this variable from acceptance models given that, empirically, it has been shown that attitude does not mediate the relationship between the perception of ease of use or usefulness and the intention to use information technology $[6,18]$.

Additionally, and notwithstanding the extremely innovative approach used by Devolder et al. (2012) [16], the authors do not demonstrate the invariance of the measurement models of each group analyzed, and consequently, they do not perform an analysis of statistically significant differences among the groups. We have not found any subsequent literature that addresses these gaps. Considering the previous ideas, a study is necessary that focuses on differences among groups of users with different psychological profiles in a structural model based on the variables and relationships established in UTAUT. Therefore, this study aims to examine the influence of personality types on the acceptance of an information system at work, particularly an ERP system, using UTAUT as a theoretical model.

\section{Literature Review}

\subsection{ERP Systems and Sustainability}

Enterprise Resource Planning (ERP) is an information technology system that supports the business functions that companies adapt to gain competitive advantages and development possibilities [19]. As Pohludka and Stverkova (2018) [1] pointed out, the primary strategic objectives of each organization include long-term growth and sustainability, which can be achieved while ensuring that the firm's organizational structure and operations are properly set by an ERP system. ERP systems can also help companies to reach desirable outcomes, which is in line with a sustainable organization in a business setting [20]. 
The literature has reported some research that associates ERP systems and sustainability. For example, rooted in a case study, Frazee and Avenue (2012) [21] discuss a successful ERP selection and implementation project for continuous operations improvement and sustainability of the organization. In a more recent study, Pohludka and Stverkova (2018) [1] investigated factors associated with the implementation and unification of an ERP system with a customer relationship management system (CRM) and their influence on the sustainable development of global companies. Based on a case study, the authors proposed a cognitive model to understand such impact. They concluded that after the implementation of the ERP system, organizations are positioned to grow and pursue new partnership opportunities sustainably. Park (2018) [19] studied the relationship between business process reengineering (BPR) and change management for the sustainable implementation of an ERP system. To this end, the author proposed a research model that includes the depth of BPR and change management as direct antecedents of ERP performance, which is viewed from an information orientation perspective. Thus, ERP performance is measured by information technology practices, information management practices, and information behaviors and values. The results indicated support for the central relationships of the model.

The research mentioned above shows the importance of studying ERP systems as a means to achieve competitive advantages and, at the same time, sustainability in different types of organizations. However, these studies have not considered user characteristics to better understand the implementation of the ERP systems phenomenon. This current study contributes to filling this gap and adds to social sustainability literature by suggesting that the implementation of ERP systems can be adjusted to a different type of users according to their personality types. Employees spend a significant amount of time using ERP systems in their daily operations; therefore, knowing what drives and motivates individuals is essential for them to live in harmony with their work environment. An ERP system carries out significant changes within organizations, since it varies business processes and the overall working environment, which may cause resistance among people [19,22].

\subsection{Unified Theory of Acceptance and Use of Technology (UTAUT)}

To carry out the study, we apply the conceptual framework of the Unified Theory of Acceptance and Use of Technology (UTAUT), a theory widely used to explain why some individuals are more or less prone to adopt information technology of diverse types in their work environment [23,24]. UTAUT was introduced by Venkatesh et al. (2003) [6], and it was inspired by eight previous theories that, to certain extent, explain technology usage: The Diffusion of Innovation Theory [25], The Theory of Reasoned Action [3], The Technology Acceptance Model [4], The Theory of Planned Behaviour [5], Social Cognitive Theory [26], Expectancy Confirmation Theory [27], The Model of Personal Computing Utilization [28], and the Motivational Model [29]. Based on the work mentioned above, Venkatesh et al. (2003) [6] created a unified model where the intention to use technology depends on three factors: performance expectancy, effort expectancy, and social influence. Performance expectancy (PE) refers to the degree to which an individual believes that using a system will help him/her to attain gains in job performance [6]. Effort expectancy (EE) is defined as the level of ease related to the use of any system. User-friendly technology could be easily accepted and adopted by users [6]. Social influence (SI) is defined as the degree to which an individual perceives that important others (such as relatives, colleagues, and subordinates) believe that he or she should use the new system [6].

In addition, the authors proposed that, in conjunction with behavioral intention, facilitating conditions influence the actual use of technology directly. Facilitating conditions (FC) are defined as the degree to which an individual perceives that organizational and technical infrastructure exists to support the use of a system [6]. The authors theorize that gender, age, experience, and degree of willingness moderate the hypothesized relationships. This unified model explained approximately $70 \%$ of the variance in behavioral intention, a value for which UTAUT has been widely used in different research related to diverse technologies and contexts [23,30-33]. The robustness of the UTAUT model makes it a good theory to explain ERP system adoption at work, considering the personality type of users. 


\subsection{Personality Traits (FFM) and UTAUT}

In recent decades, a consensus has emerged regarding the basic structure of personality in the form of the FFM [12]. The FFM proposes the existence of five traits, i.e., conscientiousness, agreeableness, extraversion, neuroticism, and openness, that capture the core domains of personality. Individuals with a high score in conscientiousness are kind, polite, helpful, indulgent, generous, and cooperative. Individuals with a high score on agreeableness are characterized by being reliable, responsible, organized, hard workers, and achievement oriented. Individuals that score highly in the extraversion domain can be described as sociable, extroverted, energetic, talkative, and active. A high score on neuroticism (used from the inverse perspective and named emotional stability in this study) is associated with anxious, depressed, ashamed, emotional, angry, worried, and insecure individuals. Finally, individuals with high scores in the openness dimension are identified by being imaginative, educated, curious, original, intelligent, and artistically sensitive minds [13].

Personality traits and acceptance frameworks have been a matter of research, since it has been found that cognitive-based dimensions impact technology acceptance and use. In general, research has addressed three approaches: The first stands out for considering personality traits effects as exogenous variables. The second approach is concerned predominantly, but not exclusively, with the consideration of personality traits as moderator variables. The least common (third) approach deals with personality prototypes, also stated as types and profiles, as well as with its effects in technology acceptance and use as an observed categorical moderator. Table 1 shows some of the relevant work that associates these three approaches with adoption frameworks and personality measures. The three approaches are described in more detail below.

Table 1. Relevant research on personality traits and adoption models.

\begin{tabular}{|c|c|c|c|c|c|}
\hline $\begin{array}{c}\text { Personality Traits } \\
\text { Approach }\end{array}$ & Research & $\begin{array}{c}\text { Adoption } \\
\text { Frameworks }\end{array}$ & IT & Sampling & $\begin{array}{l}\text { Personality } \\
\text { Measures }\end{array}$ \\
\hline \multirow{4}{*}{ External Variables } & $\begin{array}{c}\text { Barkhi and } \\
\text { Wallace (2007) } \\
{[34]}\end{array}$ & TRA-TAM & CRM System & $\begin{array}{c}257 \\
\text { Undergraduate } \\
\text { Students }\end{array}$ & $\begin{array}{l}\text { Myers-Briggs } \\
\text { Type Indicator } \\
\text { (MBTI) }\end{array}$ \\
\hline & $\begin{array}{l}\text { Barnett et al. } \\
(2015)[35]\end{array}$ & $\begin{array}{l}\text { Adapted } \\
\text { UTAUT }\end{array}$ & Custom LMS & $\begin{array}{c}382 \\
\text { Undergraduate } \\
\text { Students }\end{array}$ & $\begin{array}{l}\text { International } \\
\text { Personality } \\
\text { Item Pool }\end{array}$ \\
\hline & $\begin{array}{l}\text { Altanopoulou } \\
\text { and Tselios } \\
(2017)[36]\end{array}$ & TAM-UTAUT & Wiki System & $\begin{array}{c}\text { Pretest 85; Post-test } \\
86 \text { Undergraduate } \\
\text { Students }\end{array}$ & $\begin{array}{l}\text { International } \\
\text { Personality } \\
\text { Item Pool }\end{array}$ \\
\hline & $\begin{array}{l}\text { Ahmad and } \\
\text { Abdulkarim } \\
\text { (2018) [37] }\end{array}$ & TRA-TAM & $\begin{array}{l}\text { VR Second Life } \\
\text { System }\end{array}$ & $\begin{array}{c}183 \\
\text { Undergraduate } \\
\text { Students }\end{array}$ & $\begin{array}{l}\text { Myers-Briggs } \\
\text { Type Indicator } \\
\text { (MBTI) }\end{array}$ \\
\hline \multirow{3}{*}{ Moderations } & $\begin{array}{l}\text { Wang and Yang } \\
\text { (2005) [38] }\end{array}$ & UTAUT & $\begin{array}{l}\text { Online Stocking } \\
\text { System }\end{array}$ & $\begin{array}{c}196 \\
\text { Investors }\end{array}$ & $\begin{array}{l}\text { NEO-PI(Form } \\
\text { S) }\end{array}$ \\
\hline & $\begin{array}{c}\text { Devaraj, Easley, } \\
\text { and Crant } \\
\text { (2008) [39] }\end{array}$ & TRA-TAM & Collaborative System & $\begin{array}{c}180 \\
\text { MBA Students }\end{array}$ & $\begin{array}{c}\text { Neo-five-factor } \\
\text { inventory } \\
\text { (NEO-FFI) }\end{array}$ \\
\hline & Li 2016 [15] & TAM & ERP System & $\begin{array}{l}331 \\
\text { Undergradute } \\
\text { Students }\end{array}$ & FFM \\
\hline \multirow{2}{*}{$\begin{array}{l}\text { Observed } \\
\text { Categorical } \\
\text { Moderation }\end{array}$} & $\begin{array}{l}\text { Devolder et al., } \\
2012 \text { [16] }\end{array}$ & $\begin{array}{l}\text { UTAUT-TRIMult } \\
\text { framework }\end{array}$ & i-level EPR System & $\begin{array}{c}204 \\
\text { Nursing Personnel }\end{array}$ & $\begin{array}{c}\text { Ten Item } \\
\text { Personality } \\
\text { Inventory-TIPI }\end{array}$ \\
\hline & $\begin{array}{c}\text { Lakhal and } \\
\text { Khechine (2017) } \\
\text { [40] }\end{array}$ & UTAUT & $\begin{array}{l}\text { Desktop Video } \\
\text { conference }\end{array}$ & $\begin{array}{c}413 \\
\text { Undergraduate } \\
\text { Students }\end{array}$ & $\begin{array}{c}\text { Neo-five-factor } \\
\text { inventory } \\
\text { (NEO-FFI) }\end{array}$ \\
\hline
\end{tabular}

Source: authors' compilation. 


\subsubsection{Personality Traits as Exogenous Variables}

Based on personality Myers-Briggs Type Indicator (MBTI) and a TRA-TAM research model, Barkhi and Wallace (2007) [34] hypothesized that the intuitive/sensing dimension positively impacted perceived ease of use (PEU), the thinking/feeling dimension positively impacted perceived usefulness (PU), and the extrovert/introvert and perceptive/judging dimensions positively impacted peer influence. In this study, the relationship between thinking/feeling and PU was not confirmed [34]. Barnett et al. (2015) [35] explored the effect of the FFM components as external variables within the UTAUT conceptual framework in the context of a web-based classroom system. The authors considered only four FFM traits, excluding the agreeableness component. The proposed research model addressed both direct and partial mediated effects between FFM personality dimensions and perceived and actual system use. The results showed that the significant relationship was direct and not mediated by expressed behavioral intention. Only conscientiousness and neuroticism had a statistically significant relationship with perceived and actual system use [35]. In a more recent study, Altanopoulou and Tselios (2017) [36] assessed acceptance toward wiki technology using an adapted TAM and UTAUT models, including personality traits as external variables. Personality characteristics were measured by using the FFM model. In two case scenarios, before and after the actual use, personality dimensions were supposed to have a positive effect on PEU and SI. As a result, considering just the personality traits effects, only one relationship was statistically significant in the pre-wiki scenario. In the second model, a post-wiki scenario, three relationships showed a significant path: extraversion and agreeableness to PEU, and emotional stability to SI [36]. Finally, considering just one dimension of MBTI, introvert/extrovert, Ahmad and Abdulkarim (2018) proposed and supported the hypothesis that the personality type of individuals behind avatars was an antecedent of flow experience in virtual worlds [37].

\subsubsection{Personality Traits as Moderator Variables}

In the second approach, there are three studies worthy of mention. First, based on the UTAUT research model, Wang and Yang (2005) [38] theorized mediating effects between personality traits and intention to adopt online stocking system through UTAUT exogenous variables. Additionally, they proposed that the relation between UTAUT exogenous variables and the independent construct would be moderated by the combined action of personality traits and internet experience. The results supported some mediating effect of extraversion and openness. Also, the results substantiated the moderating effects of openness, agreeableness, conscientiousness, and neuroticism [38]. Second, based on a TRA-TAM composed research model, Devaraj et al. (2008) [39] explored the direct effect of FFM traits on perceived ease of use and subjective norms and a moderator effect on the intention to use a collaborative system. The results showed that neuroticism and agreeableness are associated, negatively, and positively, respectively, with PU. In terms of moderating relationships, agreeableness, conscientiousness, and extraversion moderated the relationship between subjective norms and intention to use. Conscientiousness moderated the relationship between usefulness and intention to use [39]. Lastly, Li [15] proposed a TAM based research model, adding training and subjective norms. She hypothesized direct and moderating effects. Results showed a significant direct effect between conscientiousness and PU. Additionally, openness and extraversion positively moderated the relationship between training and PU. Likewise, agreeableness positively moderated the relationship between subjective norms and PU [15].

\subsubsection{Personality Traits as Observed Categorical Moderator Variables}

In this approach, there are two relevant research studies. Devolder et al. (2012) [16] explored the acceptance of an electronic patient record. The authors used the categories associated with different technology consumers profiles according to the Technology Readiness Index (TRI), and the taxonomy of three types of personalities associated to the FFM as the theoretical basis for their study. Underpinning these two theories and the UTAUT framework as a measurement layer, the authors hypothesized that 
a subgroup, in the intersection of TRI and FFM dimension, would have different degrees of explained variances and dissimilar predictors. Based on the research results, the hypothesis was supported [16]. Lakhal and Khechine (2017) [40], also based on the UTAUT framework, considered the FFM as a direct effect to exogenous UTAUT constructs. Furthermore, they examined the research model across male and female groups. In the overall model, the results indicated that neuroticism negatively impacted $\mathrm{PE}, \mathrm{EE}$, and FC, and that agreeableness and conscientiousness had a positive effect on EE. In the model for the female group, agreeableness and conscientiousness had a positive effect on EE, while in the model for the male group, neuroticism negatively impacted PE, EE, and FC [40].

As a general review, we found broad and varied support for the personality dimensions to be considered as a predictor of TAM and UTAUT model constructs. In the context of the TAM model, personality traits have been considered as a direct predictor of PU and PEU. As for moderating variables, personality traits have impacted relationships between SI and PU to intention to use a system, and between SI and training to PU. Regarding the UTAUT model, personality dimensions have been tested as a direct predictor of use, both perceived and actual, and exogenous UTAUT constructs. Also, personality traits have been tested in mediating actions through intention-behavior to use, and through exogenous UTAUT constructs to intention-behavior. In terms of moderating effects, personality dimension has been used between exogenous UTAUT constructs and intention-behavior variable. Finally, observed categorical moderation has been used for testing the UTAUT model, considering both gender and personality traits as categorical moderating variables.

\subsection{Personality Types}

According to Solís-Cámara et al. (2018) [41], the personality literature based on the FFM describes two primary approaches. The first approach focuses on the variable and conceptualizes the personality in terms of differences between individuals. The second centers on the person, and is based on the configuration of a set of attributes that define each individual, grouping individuals with a similar personality pattern and exploring the relationships of these groups with variables of interest. Although the first approach has dominated psychological research, in recent decades, the importance of the person-centered approach has also been emphasized [42]. The motivation of this last approach arises from the seminal study of Block (1971) [43], and although the typology proposed by Block could not be replicated [44], its formulation served as the basis for the work of Robins et al. (1996) [45]. Robins and colleagues identified, for the first time, three personality types that have been subsequently confirmed through diverse replicates [42]. These types were called resilient, over-controlled, and under-controlled. Resilient people show high scores in emotional stability and relatively high scores in the rest of the dimensions; these individuals are described as emotionally stable, assertive, and kind. Over-controlled people have low scores in both emotional stability and extraversion and relatively low or average scores in the other dimensions; these individuals are characterized as emotionally fragile and introverted. Finally, under-controlled people have low scores in agreeableness and consciousness and average scores in the other dimensions; these individuals are indicated as people without self-control and who are highly impulsive.

At present, and although there is evidence about the existence of personality types, there is also controversy regarding the number of types and the configuration of the traits of each type [41,46]. For example, the study of Kövi et al. (2019) [42], which used a sample of 15,529 participants including 23 subsamples from 22 countries and with 16 different languages, proposes the existence of five types of personalities: over-controlled, resilient, under-controlled, reserved, and ordinary. On the other hand, the study of Gerlach et al. (2018) [12], based on the analysis of four large datasets comprising a total of more than 1.5 million participants, identified four types: reserved, self-centered, role model, and average.

Regardless of the controversies described above, there are advantages of the personality type approach to the analysis of human behavior. According to Donnellan and Robins (2010) [44], these benefits can be described as follows. First, its high level of abstraction contributes to creating 
knowledge focusing on the common characteristics of individuals. Second, it shifts attention to how traits are organized and integrated within individuals. Third, it is useful in helping to describe the findings of personality research to the general public. Finally, it serves to propose efficient moderating variables to understand why individuals have different responses to everyday events. In this study, the personality type approach was used based on the traits approach.

\section{Research Model and Hypotheses}

Based on the evidence provided by the studies mentioned above, the following hypotheses are set and depicted in Figure 1:

HO(a): Statistically significant differences between personality types exist in the adoption of the ERP system scores.

H0(b): Statistically significant differences between personality types exist in the relationships between variables of adoption of the ERP system.

H1: Performance expectancy is positively related to behavioral intention to use the ERP system.

H2: Effort expectancy is positively related to behavioral intention to use the ERP system.

H3: Social expectancy is positively related to behavioral intention to use the ERP system.

H4: Facilitating conditions is positively related to behavioral intention to use the ERP system.

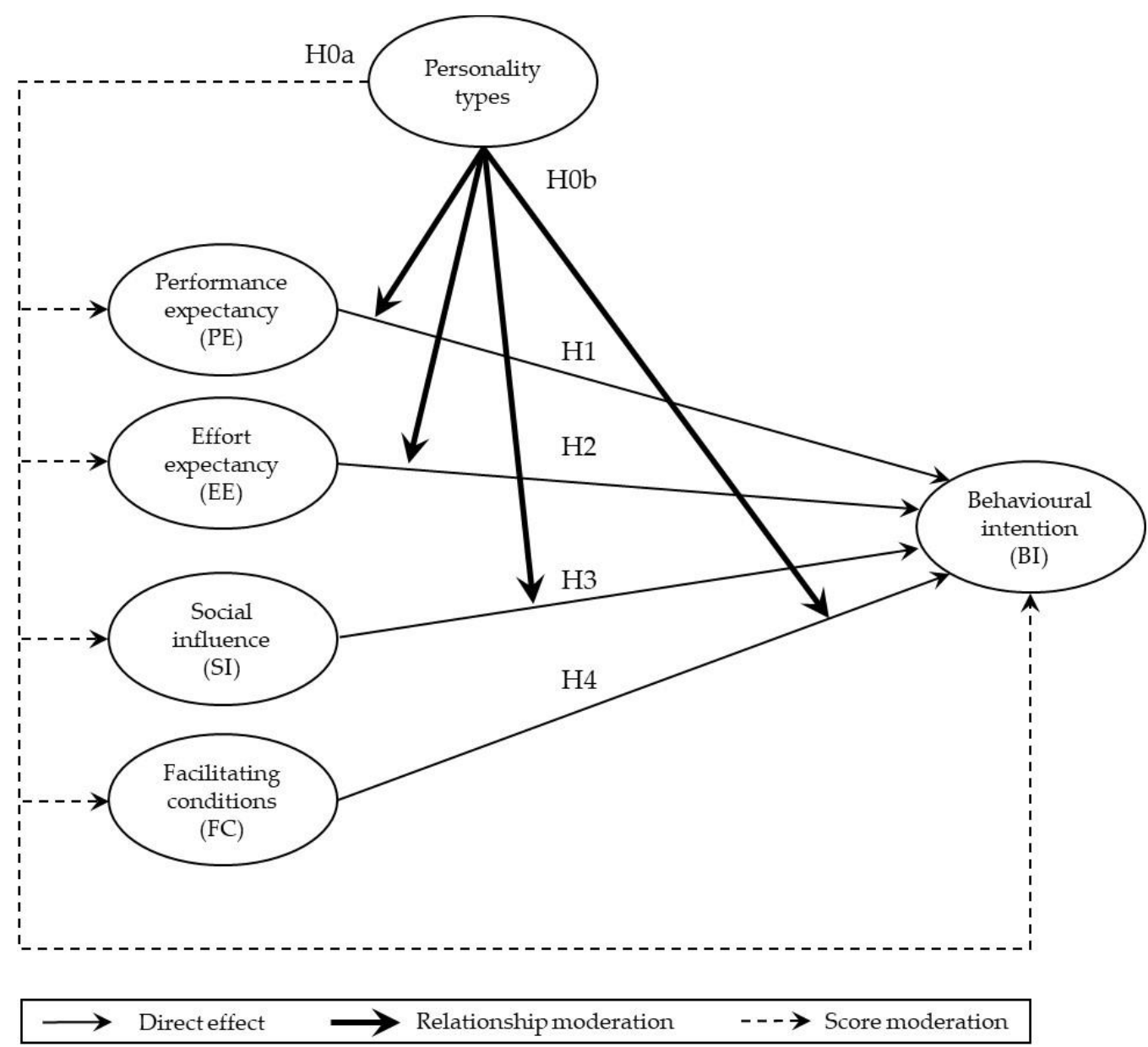

Figure 1. Research model. 


\section{Materials and Methods}

An online survey was utilized to collect data from users of ERP systems in two Chilean organizations. A total of 155 users provided valid responses. The data collection process lasted a month. Users were informed that their responses would be kept confidential, and their participation completely anonymous. In the sample, $67.1 \%$ were male, $59.4 \%$ were under thirty years old, $25.2 \%$ were between thirty and fifty years old, and $15.5 \%$ were older than fifty. These users had an average of 10.8 years of experience in the use of information technology, and $85.2 \%$ of them had tertiary education. UTAUT variables were operationalized using the scales adapted from UTAUT [6]. UTAUT items were measured on a five-point Likert scale ranging from "strongly disagree" (1) to "strongly agree" (5). FFM was measured using the Spanish-translated version the Ten-Item Personality Inventory (TIPI) scale [47] made by [48].

The Partial Least Squares (PLS) technique was used to analyze the data. Even though consistent PLS (PLSc) is recommended when latent variables are measured as reflective type [49], as in the case of the proposed research model, we used PLS instead of PLSc in this study for two reasons. First, the purpose of this study is to predict, and in prediction-oriented research, the PLSc shows no advantages over PLS. Second, we required the latent variables scores in order to perform the analysis of differences among the groups, which PLSc does not provide.

\section{Results}

\subsection{Cluster Analysis}

Table 2 shows the results of the two-step cluster analysis; this procedure identified three clusters. Clusters have been labeled Type 1, Type 2, and Type 3. Type 1 is the smallest cluster in size and corresponds to $23.2 \%$ of the sample; in this cluster, the personality traits emotional stability, extraversion, openness, and conscientiousness are the highest mean value compared with the other two clusters. The exception to this pattern is the personality trait agreeableness, which has the lowest mean value compared with the other two clusters. The personality factor with the highest mean value in this cluster is conscientiousness. Type 2 is a medium-sized cluster that corresponds to $36.1 \%$ of the sample. In this cluster, the personality dimensions extraversion, openness, and conscientiousness have a mean value lower than Type 1, but exceed Type 3. In this cluster, the factor with the highest mean z-score is agreeableness; also, this trait has the highest mean value compared with the other two clusters. The personality factor with the lowest mean value in this cluster is emotional stability. This trait also has the lowest mean value compared with the other two clusters. Type 3 is the largest cluster and corresponds to $40.7 \%$ of the sample. In this cluster, the personality dimensions extraversion, openness, and conscientiousness have the lowest mean values compared with the other two clusters. The factor with the lowest mean z-score in this cluster is conscientiousness. The personality domains emotional stability and agreeableness are ordered in a middle position between the other two clusters.

Table 2. Results of two-step cluster analysis.

\begin{tabular}{cccccccccc}
\hline \multirow{2}{*}{ FFM } & \multicolumn{9}{c}{ Clusters } \\
\cline { 2 - 10 } & \multicolumn{3}{c}{ Type 1 (23.2\%) } & \multicolumn{3}{c}{ Type 2 (36.1\%) } & \multicolumn{3}{c}{ Type 3 (40.7\%) } \\
\cline { 2 - 10 } & Z-score & Mean & SD & Z-score & Mean & SD & Z-score & Mean & SD \\
\hline Emotional stability & 0.684 & 4.056 & 0.977 & -0.948 & 1.938 & 0.701 & 0.452 & 3.754 & 1.031 \\
Extraversion & 0.895 & 4.750 & 1.099 & -0.119 & 3.554 & 0.928 & -0.406 & 3.214 & 1.069 \\
Openness & 0.750 & 6.278 & 0.779 & 0.211 & 5.661 & 0.843 & -0.616 & 4.714 & 1.149 \\
Agreeableness & -0.513 & 3.986 & 0.797 & 0.621 & 5.009 & 0.834 & -0.260 & 4.214 & 0.771 \\
Conscientiousness & 0.795 & 6.569 & 0.523 & 0.485 & 6.205 & 0.673 & -0.886 & 4.595 & 0.995 \\
\hline
\end{tabular}




\subsection{Measurement Model}

We examine the measurement and structural models separately for the complete sample and for each of the three clusters. Guidelines for the model assessment were applied according to the methods described in $[17,50]$. Table 3 shows the measurement models, outer loadings in Global and Type 3 exceed 0.75, while in Type 1 and Type 2, two and one item, correspondingly, were below 0.70 but still met literature recommendations. For the complete sample and all clusters, composite reliability and average variance extracted (AVE) exceeded the values of 0.76 and 0.53 , respectively. Consequently, convergent validity was demonstrated.

Table 3. Cronbach's Alpha, Composite Reliability, AVE, and Factor Loadings.

\begin{tabular}{|c|c|c|c|c|}
\hline Latent Variables & Global & Type 1 & Type 2 & Type 3 \\
\hline \multicolumn{5}{|l|}{ Behavioral intention to use the ERP } \\
\hline Cronbach's Alpha & 0.939 & 0.951 & 0.935 & 0.935 \\
\hline Composite Reliability & 0.961 & 0.969 & 0.959 & 0.959 \\
\hline AVE & 0.891 & 0.912 & 0.886 & 0.886 \\
\hline I intend to use the ERP in the next months & 0.928 & 0.937 & 0.945 & 0.900 \\
\hline I predict I would use the ERP in the next months & 0.948 & 0.949 & 0.931 & 0.955 \\
\hline I plan to use the ERP in the next months & 0.956 & 0.978 & 0.947 & 0.940 \\
\hline \multicolumn{5}{|l|}{ Effort expectancy } \\
\hline Cronbach's Alpha & 0.912 & 0.940 & 0.894 & 0.900 \\
\hline Composite Reliability & 0.938 & 0.957 & 0.925 & 0.930 \\
\hline AVE & 0.792 & 0.848 & 0.757 & 0.768 \\
\hline I would find the ERP easy to use & 0.862 & 0.921 & 0.765 & 0.879 \\
\hline Learning to operate the ERP is easy for me & 0.907 & 0.896 & 0.927 & 0.896 \\
\hline My interaction with the ERP would be clear and understandable & 0.916 & 0.942 & 0.922 & 0.880 \\
\hline It would be easy for me to become skillful at using the ERP & 0.873 & 0.925 & 0.856 & 0.849 \\
\hline \multicolumn{5}{|l|}{ Facilitating conditions } \\
\hline Cronbach's Alpha & 0.739 & 0.667 & 0.751 & 0.773 \\
\hline Composite Reliability & 0.851 & 0.769 & 0.856 & 0.867 \\
\hline AVE & 0.656 & 0.539 & 0.671 & 0.685 \\
\hline I have the resources necessary to use the ERP & 0.794 & 0.522 & 0.908 & 0.768 \\
\hline I have the knowledge necessary to use the ERP & 0.858 & 0.695 & 0.908 & 0.871 \\
\hline The ERP is compatible with other systems I use & 0.777 & 0.928 & 0.604 & 0.840 \\
\hline \multicolumn{5}{|l|}{ Performance expectancy } \\
\hline Cronbach's Alpha & 0.951 & 0.968 & 0.937 & 0.948 \\
\hline Composite Reliability & 0.963 & 0.975 & 0.952 & 0.960 \\
\hline AVE & 0.838 & 0.886 & 0.798 & 0.829 \\
\hline Using the ERP increases my productivity & 0.920 & 0.947 & 0.903 & 0.906 \\
\hline Using the ERP enables me to accomplish tasks more quickly & 0.912 & 0.946 & 0.894 & 0.908 \\
\hline I would find the ERP useful in my job & 0.872 & 0.906 & 0.846 & 0.859 \\
\hline Using the ERP would improve my job performance & 0.942 & 0.965 & 0.913 & 0.942 \\
\hline Using the ERP would enhance my effectiveness on the job & 0.930 & 0.941 & 0.908 & .936 \\
\hline \multicolumn{5}{|l|}{ Social influence } \\
\hline Cronbach's Alpha & 0.948 & 0.954 & 0.939 & 0.954 \\
\hline Composite Reliability & 0.967 & 0.970 & 0.961 & 0.971 \\
\hline AVE & 0.906 & 0.916 & 0.891 & 0.917 \\
\hline People who are important to me think that I should use the ERP & 0.950 & 0.962 & 0.943 & 0.946 \\
\hline People who influence my behavior think that I should use the ERP & 0.950 & 0.957 & 0.927 & 0.971 \\
\hline People whose opinions I value prefer that I use the ERP & 0.956 & 0.952 & 0.961 & 0.955 \\
\hline
\end{tabular}

Discriminant validity was evaluated following both the Fornell-Larcker criterion and the heterotrait-monotrait ratio of correlations (HTMT) approach. Table 4 shows the results for the complete sample, the square roots of the AVEs for the latent variables were higher than the correlations between them; moreover, HTMT values were all below 0.80 , providing extra support for discriminant validity. 
Table 4. Discriminant validity analysis.

\begin{tabular}{|c|c|c|c|c|c|}
\hline Latent Variable & BI & EE & FC & PE & SI \\
\hline \multicolumn{6}{|c|}{ Fornell-Larcker criterion } \\
\hline $\mathrm{BI}$ & 0.944 & & & & \\
\hline EE & 0.684 & 0.890 & & & \\
\hline FC & 0.447 & 0.610 & 0.810 & & \\
\hline PE & 0.698 & 0.707 & 0.498 & 0.915 & \\
\hline SI & 0.595 & 0.431 & 0.226 & 0.604 & 0.952 \\
\hline \multicolumn{6}{|c|}{ Heterotrait-Monotrait Ratio } \\
\hline $\mathrm{EE}$ & 0.738 & & & & \\
\hline FC & 0.531 & 0.735 & & & \\
\hline PE & 0.735 & 0.759 & 0.582 & & \\
\hline SI & 0.630 & 0.461 & 0.264 & 0.633 & \\
\hline
\end{tabular}

\subsection{Structural Model}

Table 5 shows the results of the analysis of the structural model. The examination of the structural models started with the evaluation of the Standardized Root Mean Square Residual (SRMR) for the estimated models. The global model achieves an SRMR of 0.06, and the clusters achieve SRMR values between 0.07 and 0.10 , which means adequate adjustment, according to the cut-off of 0.10 . In general, the $\mathrm{R}^{2}$ of $\mathrm{BI}$ can be considered moderate to substantial, ranging from 0.60 to 0.69 . Similarly, the $\mathrm{Q}^{2}$ of $\mathrm{BI}$ indicates that the predictive accuracy for two models is considerable (Global and Type 1); the $\mathrm{Q}^{2}$ of Type 1 is the highest of all (0.57).

Table 5. Path coefficients and indexes of structural models.

\begin{tabular}{ccccc}
\hline Relationships/Indexes & Global & Type 1 & Type 2 & Type 3 \\
\hline $\mathrm{EE} \rightarrow \mathrm{BI}$ & $0.361^{* * *}$ & $0.380 \mathrm{~ns}$ & $0.403^{*}$ & $0.128 \mathrm{~ns}$ \\
$\mathrm{FC} \rightarrow \mathrm{BI}$ & $0.036 \mathrm{~ns}$ & $-0.024 \mathrm{~ns}$ & $0.387^{* *}$ & $0.009 \mathrm{~ns}$ \\
$\mathrm{PE} \rightarrow \mathrm{BI}$ & $0.259^{* *}$ & $0.185 \mathrm{~ns}$ & $-0.066 \mathrm{~ns}$ & $0.523^{* * *}$ \\
$\mathrm{SI} \rightarrow \mathrm{BI}$ & $0.276^{* * *}$ & $0.357^{*}$ & $0.259^{* *}$ & $0.242^{*}$ \\
$\mathrm{R}^{2}$ of BI & 0.607 & 0.695 & 0.602 & 0.657 \\
$\mathrm{R}^{2}$ Adjusted of BI & 0.596 & 0.656 & 0.571 & 0.633 \\
$\mathrm{Q}^{2}$ of BI & 0.505 & 0.574 & 0.416 & 0.486 \\
SRMR & 0.065 & 0.084 & 0.100 & 0.074 \\
\hline
\end{tabular}

Next, we examined the hypothesized relationships. For the Global model, beta coefficients are positives and significant for the relationships between EE and BI, between PE and BI, and between SI and BI, but not for the relationship between FC and BI. Therefore, hypotheses H1, H2, and H3 are supported for the Global model. The analysis of relationships in clusters indicates different results. For the Type 1 model, only the beta coefficient for the relationship between SI and BI is positive and significant. For the Type 2 model, the beta coefficients are positives and significant for the relationships between EE and BI, between FC and BI, between SI and BI. Finally, for the Type 3 model, the beta coefficients are positives and significant for the relations between PE and BI, and between SI and BI. Consequently, hypothesis H4 is supported only in the Type 2 model.

\subsection{Multi-Group Analysis}

Before performing the Multi-Group Analysis, the invariance of the measurements was evaluated to ensure that any difference observed in the coefficients of the structural model between the clusters, particularly in the path coefficients, was not due to differences in the measurement model. The result of this evaluation provides support for the invariance and equivalence of the measurement. As shown in 
Table 6, ANOVA test results indicate statistically significant differences between the mean of z-scores among the three clusters for the latent variable BI. The Kruskal-Wallis non-parametric test provides similar results. For BI, mean z-scores are ordered from highest to lowest as follows: Type 2, Type 3, and Type 1 . Therefore, hypothesis H0(a) is supported partially.

Table 6. Mean values (z-scores).

\begin{tabular}{cccc}
\hline Latent Variable & Type 1 & Type 2 & Type 3 \\
\hline $\mathrm{BI}^{*}$ & -0.279 & 0.298 & -0.106 \\
$\mathrm{EE}$ & -0.209 & 0.160 & -0.023 \\
$\mathrm{FC}$ & -0.061 & 0.042 & -0.002 \\
PE & -0.184 & 0.162 & -0.039 \\
SI & 0.013 & 0.113 & -0.107 \\
\hline
\end{tabular}

Notes: ${ }^{*} p$-value $<0.05$ (ANOVA and nonparametric Kruskal-Wallis).

The multi-group analysis using MGA-PLS detects statistically significant differences between the models for two of the four relationships; Table 7 details these results. Specifically, the relationships between FC and BI, and between PE and BI show these differences; i.e., in the first relationship in two comparisons, and the second relationship in one comparison. Therefore, hypothesis Ho(b) is partially supported.

Table 7. Results of MGA-PLS across types.

\begin{tabular}{cccc}
\hline Relationships & Diff Type 1 vs. Type 2 & Diff Type 1 vs. Type 3 & Diff Type 2 vs. Type 3 \\
\hline $\mathrm{EE} \rightarrow \mathrm{BI}$ & $0.023 \mathrm{~ns}$ & $0.253 \mathrm{~ns}$ & $0.275 \mathrm{~ns}$ \\
$\mathrm{FC} \rightarrow \mathrm{BI}$ & $0.411^{*}$ & $0.033 \mathrm{~ns}$ & $0.378^{*}$ \\
$\mathrm{PE} \rightarrow \mathrm{BI}$ & $0.252 \mathrm{~ns}$ & $0.338 \mathrm{~ns}$ & $0.590^{* * *}$ \\
$\mathrm{SI} \rightarrow \mathrm{BI}$ & $0.098 \mathrm{~ns}$ & $0.115 \mathrm{~ns}$ & $0.017 \mathrm{~ns}$ \\
\hline
\end{tabular}

Notes: ${ }^{* * *} p$-value $<0.001,{ }^{*} p$-value $<0.05$, ns non-significant.

\section{Discussion}

Although three variables explain the intention to use an ERP System globally (in order of importance, EE, SI, and PE), when studying the results by personality types, this reality changes radically. For Type 1, a personality where all traits except agreeableness possess the highest scores, only SI explains intention to use the ERP system. For Type 2, a personality that stands out for a high score in agreeableness and a low score in emotional stability, the variables EE, FC, and SI explain this intention. Finally, for Type 3, a personality that stands out for the lowest score in conscientiousness, the variables PE and SI explain the intention to use the ERP system.

When the effect of the independent variables of the model on the intention to use the ERP system is revised one by one, the following can be highlighted. Globally, SI explains the intention to use the ERP system for each personality types in which users are segmented. This result supports the importance that users place upon what others think about their behavior. This finding is in line with the results of other research conducted in Chile associated with other information technology [31,51]. On the other hand, EE is essential if users are observed as a whole, but if they are segmented by personality type, EE only affects Type 2, the set of individuals with a personality closer to what the literature terms "over-controllers" [45]. Analogously, PE globally explains the dependent variable, but if users are segmented by personality type, PE only affects Type 3, the set of individuals with a personality closer to what the literature refers to as "under-controllers" [45].

When analyzing the difference of this effect between the types, the results show how the effect in Type 3 differs with Type 2 (closer to over-controllers); that is, PE is essential for the least conscientious and more stable users, and in contrast, for the relatively more conscientious and less stable individuals, it does not have that effect. Finally, FC does not have an overall effect to explain the intention 
to use the ERP system, but for personality Type 2, FC is presented as an important variable for such an explanation. Then, in individuals with lower emotional stability and a medium level of conscientiousness, the resources available to support the use of the ERP system are significant. When analyzing the difference of this effect between the types, Type 2 differs from Type 1 and Type 3.

Relevant theoretical and practical implications can be derived from this study. From a theoretical point of view, this original study contributes to the understanding of technology adoption phenomena from a broader perspective. Previous research has focused on explaining behavior based on personal beliefs without taking into account the personality traits of the individuals. The results demonstrate that personality types differentiate individuals in terms of the intention to use technology, with the over-controlled group being the most willing to use it. This study also demonstrated the invariance of the measurement models, a procedure that contributes to a solid theoretical construction of the research model.

From a practical standpoint, this study contributes to organizations in various ways. When faced with technology implementation, particularly ERP systems, firms should consider the personality types of the employees in order to ensure a successful implementation process. Since individuals behave differently according to their personality type, training programs should be designed differently according to the three types of personality revealed in this study. Emphasis on the ease of use of the technology should be given to some groups (Type 2), while the usefulness of the technology should be emphasized to others (Type 3). Facilitating conditions offered by the organization should be stressed to users pertaining Type 2 personality type.

Even though this study followed a rigorous methodological procedure, it was not without limitations. The sample size was small and comes from two cities in the country. Future research should collect more data in order to corroborate the results obtained and to test other relationships among variables. For instance, with a larger sample size, it would be interesting to examine whether personality traits directly influence the intention to use and the actual use of ERP systems at work. Future studies could also focus on determining the intention to use other technologies, not only for work purposes, but also for hedonic and educational purposes, where personal traits can be distinguished more clearly, e.g., consumer technologies such as social network sites, music and video streaming platforms, videogames, or massive open online courses.

\section{Conclusions}

Based on the FFM (openness to experience, conscientiousness, extraversion, agreeableness, and emotional stability) and the unified theory of acceptance and use of technology, this study examined the influence of personality types on the acceptance of ERP systems at work. The cluster analysis applied to the FFM identified three different types of personalities. The multi-group analysis detected statistically significant differences among these types of personalities. For all personality types, the intention to use technology is explained more than 60 percent, however, the strength of the antecedent variables changed drastically depending on the type of personality. These findings indicate that personality type plays an essential role as a moderator of technology acceptance at work, which, in turn, could help organizations to implement technology successfully, and therefore, to contribute to their sustainability.

Author Contributions: Conceptualization, P.R.-C.; methodology, P.R.-C., and E.E.G.; data collection: P.R.-C., E.E.G., J.A.-P., and G.P.-A.; software, P.R.-C.; validation, P.R.-C., E.E.G., J.A.-P., and G.P.-A.; formal analysis, P.R.-C.; investigation, P.R.-C., E.E.G., J.A.-P., and G.P.-A.; resources, P.R.-C., and J.A.-P.; data curation, P.R.-C.; writing-original draft preparation, P.R.-C., E.E.G., J.A.-P., and G.P.-A.; writing—review and editing, P.R.-C., and E.E.G.; visualization, P.R.-C., and E.E.G.; supervision, P.R.-C.; project administration, P.R.-C., and E.E.G.; funding acquisition, P.R.-C., and J.A.-P.

Funding: This research received no external funding.

Conflicts of Interest: The authors declare no conflict of interest. 


\section{References}

1. Pohludka, M.; Stverkova, H. Implementation and unification of the ERP system in a global company as a strategic decision for sustainable entrepreneurship. Sustainability 2018, 10, 2916. [CrossRef]

2. Shiau, W.L. The intellectual core of enterprise information systems: A co-citation analysis. Enterp. Inf. Syst. 2016, 10, 815-844. [CrossRef]

3. Fishbein, M.; Ajzen, I. Belief, Attitude, Intention and Behavior: An Introduction to Theory and Research; Addison-Wesley: Boston, MA, USA, 1975; ISBN 0201020890.

4. Davis, F.D. Perceived usefulness, perceived ease of use, and user acceptance of information technology. MIS Q. 1989, 13, 319-340. [CrossRef]

5. Ajzen, I. The theory of planned behavior. Organ. Behav. Hum. Decis. Process. 1991, 50, 179-211. [CrossRef]

6. Venkatesh, V.; Morris, M.G.; Davis, G.B.; Davis, F.D. User acceptance of information technology: Toward a unified view. MIS Q. 2003, 27, 425-478. [CrossRef]

7. Zmud, R.W. Individual differences and MIS success: A review of the empirical literature. Manag. Sci. 1979, 25, 966-979. [CrossRef]

8. Dehghanzade, H. A Survey of human factors' impacts on the effectiveness of accounting information systems. Int. J. Bus. Adm. 2011, 2, 166-174. [CrossRef]

9. Uffen, J.; Guhr, N.; Breitner, M.H. Personality traits and information security management: An empirical study. In Proceedings of the Thirty Third International Conference on Information Systems, Orlando, FL, USA, 16-19 December 2012.

10. Tkalcic, M.; Quercia, D.; Graf, S. Preface to the special issue on personality in personalized systems. User Model. User-Adapt. Interact. 2016, 103-107. [CrossRef]

11. Sharp, J.H.; Babb, J.S. Is information systems late to the party? The current state of DevOps research in the Association for Information Systems eLibrary. In Proceedings of the Twenty-Fourth American Conference on Information Systems, Orlando, FL, USA, 16-18 August 2018; pp. 1-8.

12. Gerlach, M.; Farb, B.; Revelle, W.; Amaral, L.A.N. A robust data-driven approach identifies four personality types across four large data sets. Nat. Hum. Behav. 2018, 2, 735-742. [CrossRef]

13. Costa, P.T.; McCrae, R.R. Professional manual: Revised NEO personality inventory (NEO-PI-R) and NEO five-factor inventory (NEO-FFI). Odessa FL Psychol. Assess. Resour. 1992. [CrossRef]

14. Lin, M.Y.; Ong, C. Understanding information systems continuance intention: A five-factor model of personality perspective. Pac. Asia Conf. Inf. Syst. 2009, 1, 367-376.

15. Li, C.Y. Understanding university students' system acceptance behavior: The roles of personality trait and subjective norms. Int. J. Technol. Hum. Interact. 2016, 12, 106-125. [CrossRef]

16. Devolder, P.; Pynoo, B.; Sijnave, B.; Voet, T.; Duyck, P. Framework for user acceptance: Clustering for fine-grained results. Inf. Manag. 2012, 49, 233-239. [CrossRef]

17. Hair, J.F.J.; Hult, G.T.M.; Ringle, C.; Sarstedt, M. A Primer on Partial Least Squares Structural Equation Modeling (PLS-SEM), 2nd ed.; SAGE Publishing: New York, NY, USA, 2016; ISBN 9781452217444.

18. Venkatesh, V.; Speier, C. Creating an effective training environment for enhancing telework. Int. J. Hum. Comput. Stud. 2000, 52, 991-1005. [CrossRef]

19. Park, K.O. The relationship between BPR strategy and change management for the sustainable implementation of ERP: An information orientation perspective. Sustainability 2018, 10, 3080. [CrossRef]

20. Lin, A.J.; Chang, H. Business sustainability performance evaluation for taiwanese banks-A hybrid multiple-criteria decision-making approach. Sustainability 2019, 11, 2236. [CrossRef]

21. Frazee, K.; Avenue, H. ERP implementation for corporate growth and sustainability northeastern University. Int. J. Bus. Soc. Sci. 2012, 3, 74-82.

22. Grandón, E.E.; Ramírez-correa, P.E.; Rojas, K.P. Uso de la teoría Business Process Change (BPC) para examinar la adopción de Enterprise Resource Planning (ERP) en Chile. Interciencia 2018, 43, 716-722.

23. Lee, J.; Kim, K.; Shin, H.; Hwang, J. Acceptance factors of appropriate technology: Case of water purification systems in Binh Dinh, Vietnam. Sustainability 2018, 10, 2255. [CrossRef]

24. Palau-Saumell, R.; Forgas-Coll, S.; Javier, S. User acceptance of mobile apps for restaurants: An expanded and extended UTAUT-2. Sustainability 2019, 11, 1210. [CrossRef]

25. Rogers, E. Difussion of Innovations; Free Press: New York, NY, USA, 1962; ISBN 0029266718. 
26. Compeau, D.; Higgins, C.A.; Huff, S. Social cognitive theory and individual reactions to computing technology: A longitudinal. MIS Q. 1999, 23, 145-158. [CrossRef]

27. Oliver, R.L. A Cognitive Model of the antecedents and consequences of satisfaction decisions. J. Mark. Res. 1980, 17, 460-469. [CrossRef]

28. Thompson, R.L.; Higgins, C.A.; Howell, J.M. Personal computing: Toward a conceptual model of utilization. MIS Q. 1991, 15, 125-143. [CrossRef]

29. Davis, F.D.; Bagozzi, R.P.; Warshaw, P.R. Extrinsic and intrinsic motivation to use computers in the workplace. J. Appl. Soc. Psychol. 1992. [CrossRef]

30. Ramírez-Correa, P.E.; Rondán-Cataluña, F.J.; Arenas-Gaitán, J. A Posteriori Segmentation of Personal Profiles of Online Video Games' Players. Games Cult. 2018. [CrossRef]

31. López-Pérez, V.A.; Ramírez-Correa, P.E.; Grandón, E.E. Innovativeness and factors that affect the information technology adoption in the classroom by primary teachers in Chile. Inform. Educ. 2019, 18, 165-181. [CrossRef]

32. Grandón, E.E.; Ramírez-Correa, P. Managers/owners' innovativeness and electronic commerce acceptance in chilean smes: A multi-group analysis based on a structural equation model. J. Theor. Appl. Electron. Commer. Res. 2018. [CrossRef]

33. Ramírez-Correa, P.E.; Rondán-Cataluña, F.J.; Arenas-Gaitán, J. An Empirical Analysis of Mobile Internet Acceptance in Chile Literature Review Adoption of Mobile Internet. 2014. Available online: http:// InformationR.net/ir/19-3/paper635.html (accessed on 5 April 2019).

34. Barkhi, R.; Wallace, L. The impact of personality type on purchasing decisions in virtual stores. Inf. Technol. Manag. 2007, 8, 313-330. [CrossRef]

35. Barnett, T.; Pearson, A.W.; Pearson, R.; Kellermanns, F.W. Five-factor model personality traits as predictors of perceived and actual usage of technology. Eur. J. Inf. Syst. 2015, 24, 374-390. [CrossRef]

36. Altanopoulou, P.; Tselios, N. Assessing Acceptance Toward Wiki Technology in the Context of Higher Education. Int. Rev. Res. Open Distrib. Learn. 2017, 18, 127-149. [CrossRef]

37. Ahmad, N.; Abdulkarim, H. The Impact of Flow Experience and Personality Type on the Intention to Use Virtual World. Int. J. Hum. Comput. Interact. 2018, 1-12. [CrossRef]

38. Wang, H.-I.; Yang, H.-L. The Role of Personality Traits in UTAUT Model under Online Stocking. Contemp. Manag. Res. 2005, 1, 69-82. [CrossRef]

39. Devaraj, S.; Easley, R.E.; Crant, J.M. How does personality matter? Relating the five-factor model to technology acceptance and use. Inf. Syst. Res. 2008, 19, 93-105. [CrossRef]

40. Lakhal, S.; Khechine, H. Relating personality (Big Five) to the core constructs of the Unified Theory of Acceptance and Use of Technology. J. Comput. Educ. 2017, 4, 251-282. [CrossRef]

41. Solís-Cámara, P.; Meda Lara, R.M.; Moreno Jiménez, B.; Palomera Chávez, A.; Juárez Rodríguez, P. Comparación de la salud subjetiva entre prototipos de personalidad recuperados en población general de México. Acta Colomb. Psicol. 2018. [CrossRef]

42. Kövi, Z.; Aluja, A.; Glicksohn, J.; Blanch, A.; Morizot, J.; Wang, W.; Barry, O.; Hansenne, M.; Carvalho, A.; Valdivia, M.; et al. Cross-country analysis of alternative five factor personality trait profiles. Pers. Individ. Dif. 2019. [CrossRef]

43. Block, J. Lives through Time; Psychology Press: Hove, UK, 1971; ISBN 1317766466.

44. Donnellan, M.B.; Robins, R.W. Resilient, Overcontrolled, and Undercontrolled Personality Types: Issues and Controversies. Soc. Pers. Psychol. Compass 2010. [CrossRef]

45. Robins, R.W.; John, O.P.; Caspi, A.; Moffitt, T.E.; Stouthamer-Loeber, M. Resilient, Overcontrolled, and Undercontrolled Boys: Three Replicable Personality Types. J. Pers. Soc. Psychol. 1996. [CrossRef]

46. Sârbescu, P.; Boncu, A. The resilient, the restraint and the restless: Personality types based on the Alternative Five-Factor Model. Pers. Individ. Dif. 2018. [CrossRef]

47. Gosling, S.D.; Rentfrow, P.J.; Swann, W.B. A very brief measure of the Big-Five personality domains. J. Res. Pers. 2003. [CrossRef]

48. Romero, E.; Villar, P.; Gómez-Fraguela, J.A.; López-Romero, L. Measuring personality traits with ultra-short scales: A study of the Ten Item Personality Inventory (TIPI) in a Spanish sample. Pers. Individ. Dif. 2012. [CrossRef]

49. Cepeda-Carrion, G.; Cegarra-Navarro, J.G.; Cillo, V. Tips to use partial least squares structural equation modelling (PLS-SEM) in knowledge management. J. Knowl. Manag. 2019, 23, 67-89. [CrossRef] 
50. Hair, J.F.; Risher, J.J.; Sarstedt, M.; Ringle, C.M. When to use and how to report the results of PLS-SEM. Eur. Bus. Rev. 2019, 31, 2-24. [CrossRef]

51. Grandón, E.E.; Aravena Ibarra, A.; Araya Guzman, S.; Ramirez-Correa, P.; Alfaro-Perez, J. Internet de las Cosas: Factores que influyen su adopción en Pymes chilenas. In Proceedings of the CISTI 2018-13th Iberian Conference on Information Systems and Technologies, Caceres, Spain, 13-16 June 2018; pp. 1-6.

(C) 2019 by the authors. Licensee MDPI, Basel, Switzerland. This article is an open access article distributed under the terms and conditions of the Creative Commons Attribution (CC BY) license (http://creativecommons.org/licenses/by/4.0/). 